\title{
Usability Testing of a Web Portal for Ornamental Plants and Flowers in Arusha, Tanzania
}

\author{
Kenneth Patrick Asiimwe \\ School of Computational and \\ Communication Sciences and \\ Engineering \\ Nelson Mandela African Institute of \\ Science and Technology \\ Arusha, Tanzania \\ patricka@nm-aist.ac.tz
}

\author{
Dina Machuve \\ School of Computational and \\ Communication Sciences and \\ Engineering \\ Nelson Mandela African Institute of \\ Science and Technology \\ Arusha, Tanzania \\ dina.machuve@nm-aist.ac.tz
}

\author{
Mussa Ally Dida \\ School of Computational and \\ Communication Sciences and \\ Engineering \\ Nelson Mandela African Institute of \\ Science and Technology \\ Arusha, Tanzania \\ mussa.ally@nm-aist.ac.tz
}

\begin{abstract}
The Information and Communication Technology (ICT) adoption has steadily advanced in the horticulture sector in Tanzania. This study aims to test and give feedback regarding the usability of a developed web portal prototype for ornamental plants and flowers in Arusha City. The stakeholders are botanists and researchers who search for plant and flower information (taxonomy), small scale farmers, herbalists, and the Arusha City Council. The assessments were organized and conducted in groups where each stakeholder was given access to the web portal for 2 days. Questionnaires were distributed to get feedback from each participant (a total of 48 participants). Multicriteria satisfaction analysis was chosen to measure user satisfaction measuring usability factors such as service quality, technical quality, information quality, and system quality. The overall obtained results had a mean score above $3.5(70 \%)$ on a fivepoint scale Likert scale analysis.
\end{abstract}

Keywords-usability testing; web portal; user requirement satisfaction

\section{INTRODUCTION}

Web portals are gateways for the exchange of services and information with the use of simple user interfaces, a significant role in recent advancement of Information and Communication Technology (ICT) [1]. These portals enable database access, new user's registration and search capabilities. Therefore, their performance is very significant [2]. In Africa, ornamental production, a subsector of horticulture, has developed in the past decade with Kenya ranking first, followed by Tanzania, South Africa, and Uganda. This is attributed to the adoption of ICT and technology in the ornamental sector in Africa [3]. However, the adoption of ICT in horticultural production is still a challenge [4]. The horticulture sector in Arusha City is dominated mainly by small-scale farmers (vendors) selling ornamental plants and flowers mostly on road sides (streets) contributing to about $70 \%$ of the production in the sector, without being directly connected to the regional and international market [5]. Furthermore, horticulture in Tanzania is challenged with inadequate access to information by stakeholders, including researchers and buyers. Also, there is a lack of awareness by stakeholders in Tanzania and internationally about the economic and social potential of the horticulture sector [6]. The access to information on varying species of ornamental plants and flowers in Tanzania is limited [5]. It is therefore important to test the usability of the developed web portal to ensure the user needs are met. With the advancement of ICT in the $21 \mathrm{st}$ century, access to information at anytime, anyplace with little effort should be possible. Poorly designed interfaces hinder the effectiveness of a system [7]. Additionally, according to [8], they bring low financial returns as many clients will seek alternative web systems that are better designed and have good user experience.

Many horticulture institutions in Tanzania specifically have attempted to adopt the use of web portals, especially third party portals such as BRAHMS (Botanical Research and Herbarium Management System) to provide their services. Such portals store and share information on a variety of species of plants in the country, in other words they provide a digitization of the biodiversity collection of various horticulture institutions in the country. Since these services are offered mainly by third parties, it is required that the efforts to ensure the achievements of their purpose must satisfy all stakeholder expectations measured on the level of user satisfaction by all the end users of the system. The third party web portal used in Tanzania (BRAHMS) is designed specifically for botanical collections and uses the obsolete Disk Operating System (DOS) [9] which is not easily understood by common users. It does not have a Graphical User Interface (GUI) which challenges user experience. Therefore, this study aims to test the usability of the developed prototype web portal for ornamental plants and flowers in Arusha City, to gather the user requirements, to measure user satisfaction, and to give feedback for the continuous enhancement of the portal. A website that is not user friendly does not attract users, it rather drives them away, thus it is crucial that a user-centered approach is followed in order to ensure usability and thus attract more users [10].

The developed web portal has two parts, one is client side where the information on the variety species of ornamental plants and flowers can be accessed and vendor ads on various products are showcased, the second is the server side which

Corresponding author: Kenneth Patrick Asiimwe 
allows the administrator to register or add information on the species including: English name, botanical name, family name, origin, vernacular name, trade name, description by size, shape, color, genus, image, use (medicinal or herbal, edible or poisonous, and ornamental), and also a conservation in terms of quantity (extinct in the wild, extinct, critically endangered, endangered, least concern vulnerable, nearly threatened, data deficient, and not evaluated).

\section{USABILITY TESTING}

Usability testing is a technique of getting feedback from stakeholders about a product in order to ensure it meets their requirements [11]. Usability is the most significant feature or aspect of an application [7]. According to [12], Human Computer Interaction (HCI) does not only involve ease of use but also proved easy access to information and thus users today are much now interested in user interfaces that are effective and easy to learn. It is for developers to spend much time in developing user interface and the outcomes of [13] show that in today's application development, an average of $50 \%$ of the total time is spent on implementing user interface. This study therefore focused on the usability testing of the developed web portal prototype to ensure that it meets user requirements. According to [14] and to a certain extent, usability is no more significant than user acceptability as people may not find the system acceptable even when it scores highly on effectiveness and efficiency. This study therefore focuses on measuring user acceptance to determine user acceptability. There are several methods for measuring usability [8]. According to [15], the most used methods are statistical: conjoint analysis, discriminant analysis, multiple regression analysis, and Multicriteria Satisfaction Analysis (MUSA) which uses ordinal regression analysis among others. Usability factors, namely: service quality, technical quality, information quality, and system quality are chosen to measure user satisfaction of the developed web portal. This study therefore aims to analyze ease of use, efficiency, interaction, navigation, learnability, responsiveness, and satisfaction (Figure 1). MUSA is recommended as a model of measuring user satisfaction. According to [16] there is no clear consensus on how to measure usability but a mean score value that is significant and meaningful is recommended. For this study, a mean score on a five-point scale Likert scale was used to determine user acceptance of the developed web portal for ornamental plants and flowers and MUSA was adopted to measure satisfaction. The main purpose of this usability test is to make sure that the user requirements are met and to get feedback from the users in order to redesign or make changes that will improve the web portal's performance.

\section{A. Implementation of the Web Portal Prototype}

The developed web portal for ornamental plants and flowers provides various services, namely: mapping and digitization of the various species of ornamental plants and flowers in Arusha City, connecting vendors of Arusha City to the regional and international market, and providing baseline information on horticulture to the Arusha City Council. The developed web portal contains two parts, the user interface or client side which is interactive, and where the users can interact with the other side which is the database that contains the information. The stakeholders of the web portal include:

- Botanists and researchers who interact with the web portal to access information stored in the database. The botanists are able to find plants' and flowers' varieties information, images, and sale locations online.

- Vendors who are able to advertise their products on the portal and conduct business with their customers online.

- The Arusha City Council representatives who access baseline information on the sector to make informed plans and decisions.

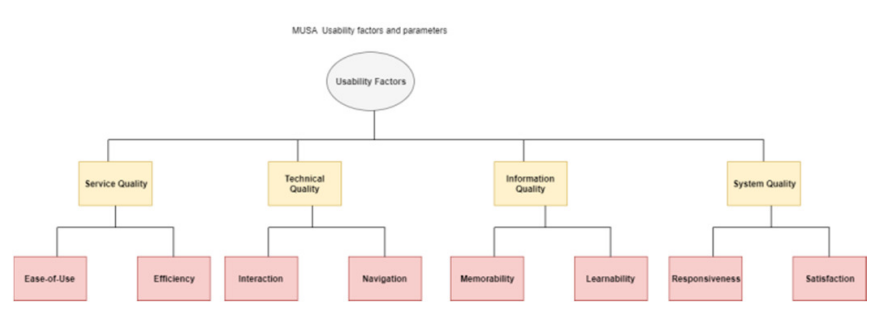

Fig. 1. Usability factors and features

In order to access the web portal, a user is required to be authenticated, i.e. the user needs login credentials. The web portal allows quick browsing of the various species of ornamental plants and flowers, quick navigation of vendors' adverts on a variety of products along with the location of the ornamental plants and flowers they are selling. The web portal also provides the administrator with an interactive interface allowing adding information on the species to the database. This information is retrieved on the client side easily via a search engine that retrieves information from the database based on user keywords making information access fast and simple for the users.

\section{Methodology}

\section{A. Participants}

The test involved 5 groups, namely botanists and researchers, herbalists, the IT staff, vendors, and Arusha City Council representatives. The participants were 48 in total. Four were botanists and researchers employed at TPRI, 1 was a herbalist at the TPRI, 1 was an IT officer in charge of the database for the collected species at TPRI, 1 was staff from the Arusha City Council and the other 41 were Arusha vendors, growing and selling these species as shown in Table I.

TABLE I. PARTICIPANTS DISTRIBUTION

\begin{tabular}{|c|c|}
\hline Participants & Number \\
\hline Botanists and researchers & 4 \\
\hline IT officers & 1 \\
\hline Arusha City Council representatives & 1 \\
\hline Vendors & 41 \\
\hline Herbalsits & 1 \\
\hline
\end{tabular}

\section{B. Testing Phases}

The participants were given access to the web portal (hosted online) through their smart devices, they were trained 
on how to navigate, and were given 2 days to use the portal to conduct their respective activities. Then, their comments and recommendations were asked. Questionnaires were used to measure the usability of the web portal of ornamental plants and flowers in Arusha City. The main objective of the first phase of the usability test was to follow up on user feedback and recommendation regarding access and usability. Thorough testing was done based on several important user requirements and a more accessible and easy to use user interface. After pretraining on usage and navigation of the web portal, the users were expected to login with their credentials after registration and approval. If the user could not login, the user could still navigate through the portal to access information on the species of plants and flowers available for sale by vendors in Arusha City. However, there are features that the users could access only after logging, e.g. advertising products, viewing and responding to orders, seeing summarized data on the sector, and the administrator could insert and process the ornamental plants and flowers and their images in the database.

The assessment was done online using browsers on smart phones and personal computers after which comments and feedback were collected form the participants regarding usability and accessibility. The main purpose was to report any errors or faults of the web portal, so they could be addressed by the developer. During testing, the stakeholders were given access via their smart devices (smart phones, laptops and personal computers) to the web portal. However, due to different backgrounds in the use of technology, the users were first given training on how to use the web portal before commencing with the usability testing. Different stages of usability testing where undertaken to achieve this objective as shown in Figure 2. The diversity of participants meant that there was a difference in the usage of smart phones and personal computers thus the users were grouped based on their knowledge and skills. The first group had better skills and knowledge on the use of smartphones and personal computers therefore required little training and the other group required more training on the navigation of the web portal. The participants' gender and age groups can be seen in Figures 3 and 4 respectively.

\section{RESULTS AND DISCUSSION}

\section{A. Results from the First Phase Test}

All the 48 participants clearly understood how to navigate the developed web portal and they were satisfied with the web portal services for inventory, mapping, digitization, and its use as a marketing tool. The participants agreed that the web portal allowed easy access of information on the species of ornamental plants and flowers available for sale in Arusha City. The test's objective was to acquire feedback on several user requirements. The acquired recommendations were: the users requested for a more user-friendly interface and a switch of languages from English to Swahili text, the scientific names of the variety species should appear in italic as it is the proper way, and the image quality of the species should be improved. From the questionnaire results, it was observed that none of the 48 participants was dissatisfied with the workability of the web portal and they recommended a few rather minor changes.
Usability Test for Web portal for Ornamental Plants and Flowers
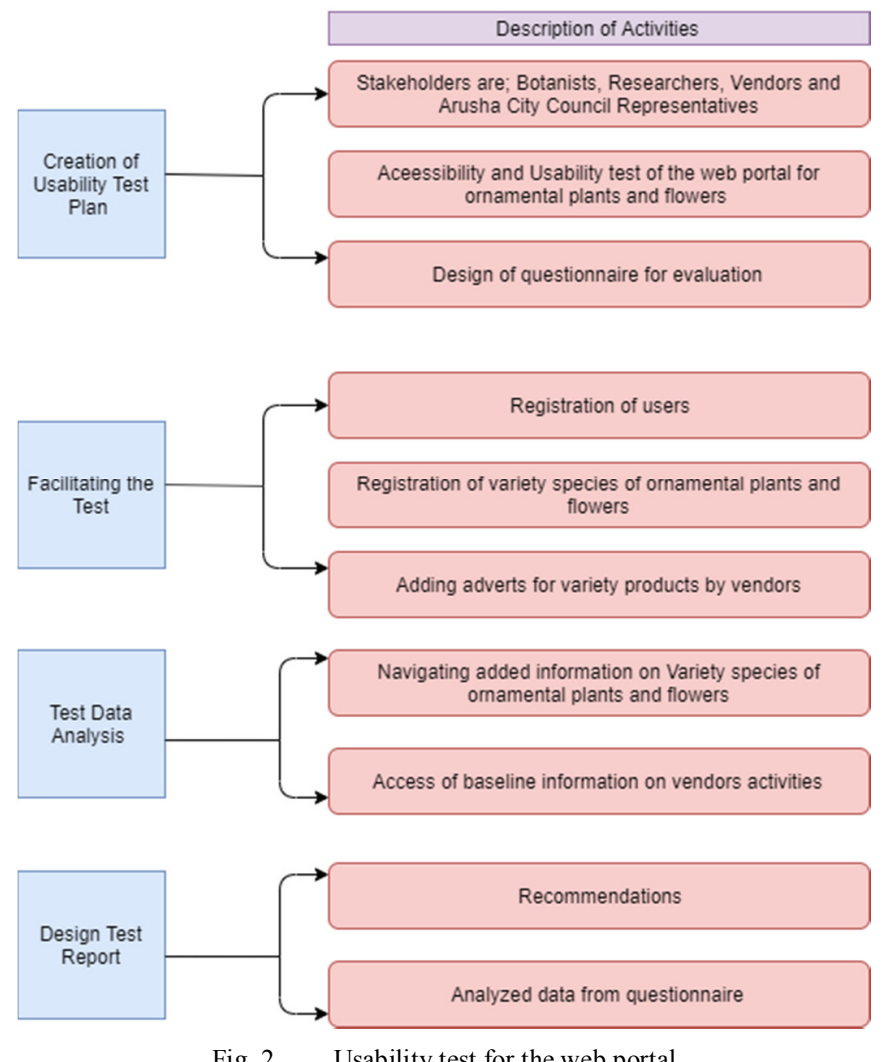

Fig. 2. Usability test for the web portal

Gender Analysis

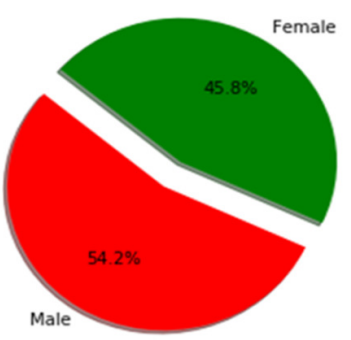

Fig. 3. Gender of respondents

\section{B. Results from the Final Phase Test of the Web Portal}

The comments and recommendations from the first phase test were addressed and the final phase test was done with the same participants to ensure that their recommendations were properly addressed and the web portal fully met their requirements. The participants were able to analyze the workability of the web portal during the final phase test based on parameters or features, namely (service quality) ease of use of the portal, (technical quality) interaction and navigation by vendors in its use as a marketing tool, (information quality) learnability for stakeholders to be able to access important information on the species of ornamental plants and flowers, and finally (system quality) satisfaction, i.e. if they would recommend the tool. The participants were allowed to interact with the system's functional units to assess their correctness 
and other performance factors like speed, easiness and responsiveness [17]. Questionnaires were distributed to different participants with the aim to find users' perception and views on the developed system based on the above mentioned parameters. The responses' mean score on a five-point scale Likert scale, where by $(5=$ Strongly Agree, $4=$ Agree, $3=$ Neutral, $2=$ Disagree and $1=$ Strongly Disagree), was computed as shown in Table II. The final phase of the test was to analyze the data from the questionnaire.

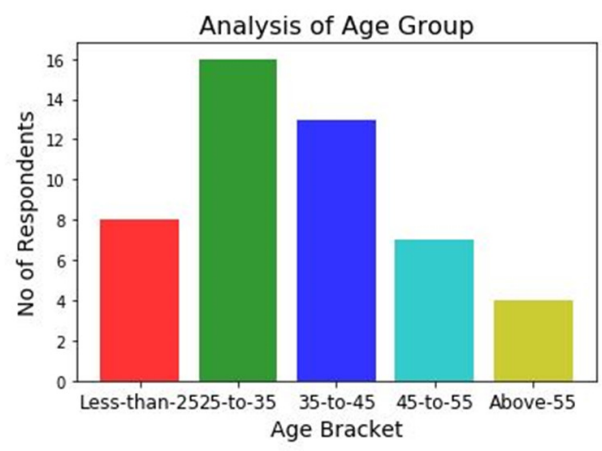

Fig. 4. Age group analysis of the respondents

TABLE II. USER ACCEPTANCE RESULTS

\begin{tabular}{|c|c|c|c|}
\hline \multirow[b]{2}{*}{$\begin{array}{l}\text { Usability } \\
\text { Factors }\end{array}$} & \multicolumn{3}{|c|}{ Usability Features } \\
\hline & Usability feature & Mean & $\begin{array}{l}\text { Standard } \\
\text { deviation }\end{array}$ \\
\hline \multirow{2}{*}{$\begin{array}{l}\text { Service } \\
\text { Quality }\end{array}$} & Ease-of-use & 4.65 & 0.56 \\
\hline & Efficiency & 4.69 & 0.55 \\
\hline \multirow{2}{*}{$\begin{array}{l}\text { Technical } \\
\text { Quality }\end{array}$} & Interaction & 4.50 & 0.58 \\
\hline & Navigation & 4.60 & 0.57 \\
\hline \multirow{2}{*}{$\begin{array}{c}\text { Information } \\
\text { Quality }\end{array}$} & Memorability & 4.48 & 0.62 \\
\hline & Learnability & 4.50 & 0.62 \\
\hline \multirow{2}{*}{$\begin{array}{l}\text { System } \\
\text { Quality }\end{array}$} & Responsiveness & 4.46 & 0.58 \\
\hline & Satisfaction & 4.63 & 0.53 \\
\hline
\end{tabular}

\section{User Acceptance Results}

During testing, user acceptance was measured with MUSA based on the 8 usability features that were arranged into 4 usability factors namely: Service Quality, Technical Quality, Information Quality, System Quality. The results are shown in Tables II-III

TABLE III. USABILITY FEATURES

\begin{tabular}{|c|l|c|}
\hline Factors & \multicolumn{1}{|c|}{ Attributes } & \% measure \\
\hline \multirow{2}{*}{$\begin{array}{c}\text { Service Quality } \\
(30 \%)\end{array}$} & A1. Ease-of-use & 16 \\
\cline { 2 - 3 } & A2. Efficiency & 14 \\
\hline Information Quality & A1. Interaction & 12 \\
\cline { 2 - 3 }$(\mathbf{2 0 \% )}$ & A2. Navigation & 8 \\
\hline Technical Quality & A1. Memorability & 8 \\
\cline { 2 - 3 }$(\mathbf{( 3 0 \% )}$ & A2. Learnability & 22 \\
\hline \multirow{2}{*}{$\begin{array}{c}\text { System Quality } \\
(\mathbf{2 0 \% )}\end{array}$} & A1. Response Time & 7 \\
\cline { 2 - 3 } & A2. Users Satisfaction & 13 \\
\hline
\end{tabular}

Regression analysis was performed on the usability features to determine the relationship between the dependent variable which is the overall quality, $\mathrm{Y}$ and independent variables representing service quality ( $\mathrm{SeQ}$ ), information quality (IQ), technical quality (TQ) and system quality (SQ). The regression model was: $Y=m X+C$.

$$
\begin{gathered}
O Q=0.647+0.841 S Q \\
O Q=1.364+0.707 I Q \\
O Q=1.13+0.765 T Q \\
O Q=0.785+0.834 S e Q
\end{gathered}
$$

The results of multiple regression carried out on all usability factors are given in (5):

$$
Y=3.147+0.841 S Q+0.707 I Q+0.765 T Q+0.834 S e Q
$$

\section{Discussion}

The mean score for each validated feature was quite high, and in any case above 3.5 which is $70 \%$ of the maximum score

\begin{tabular}{|c|c|c|}
\hline Requirement & Description & $\begin{array}{c}\text { Test } \\
\text { score }\end{array}$ \\
\hline Registration & $\begin{array}{l}\text { Web portal shall allow registration and } \\
\text { login for access of exceptional } \\
\text { information and guidance customized for } \\
\text { a specific type of users. The administrator } \\
\text { can register vendors/users. Vendors/users } \\
\text { can register themselves and await } \\
\text { approval from an administrator. }\end{array}$ & Pass \\
\hline $\begin{array}{l}\text { Manage user } \\
\text { accounts }\end{array}$ & $\begin{array}{l}\text { The administrator may add or delete users } \\
\text { and vendors. }\end{array}$ & Pass \\
\hline $\begin{array}{l}\text { Add (upload } \\
\text { images) } \\
\text { delete } \\
\text { ornamentals }\end{array}$ & $\begin{array}{l}\text { The administrator can be able to upload } \\
\text { images of the ornamentals and add } \\
\text { information of ornamental plants and } \\
\text { flowers. }\end{array}$ & Pass \\
\hline Search & $\begin{array}{l}\text { Users and administrator must have an } \\
\text { advanced search option to ease } \\
\text { information retrieval }\end{array}$ & Pass \\
\hline $\begin{array}{c}\text { View } \\
\text { ornamentals }\end{array}$ & $\begin{array}{l}\text { The system should be able to display the } \\
\text { information of ornamental plants and } \\
\text { flowers. }\end{array}$ & Pass \\
\hline Visual data & $\begin{array}{l}\text { The administrator should be able to } \\
\text { upload a CSV file in the database for } \\
\text { visualization. Users should be able to } \\
\text { select entries and perform visualization. }\end{array}$ & Pass \\
\hline Chat & $\begin{array}{l}\text { The system should provide access to chat } \\
\text { rooms for vendors, botanists, and other } \\
\text { users, store messages in chat rooms, and } \\
\text { display messages in group chat rooms }\end{array}$ & Pass \\
\hline
\end{tabular}
value as shown in Table II which indicates that the majority of the sampled respondents accepted the system and expressed their willingness to use it to conduct their business activities.

TABLE IV. SYSTEM TESTING RESULTS ON USER REQUIREMENTS

The service quality factor parameters, ease of use $(4.65$ mean and 0.56 standard deviation, which indicates that the majority of participants strongly agreed that the web portal is easy to use) and efficiency (4.69 mean and 0.55 standard deviation which meant that the service quality of the web portal is good), had the highest score. Technical quality also involved two parameters of which interaction got a mean score of 4.50 and a standard deviation of 0.58 and navigation with a mean score of 4.60 with 0.57 standard deviation which shows that participants responded positively. The third usability factor was information quality having also two parameters, namely memorability and learnability that scored 4.48 , and 0.62 , and 4.50 and 0.62 mean and standard deviation respectively. Lastly, system quality parameters, namely responsiveness with 4.46 mean and 0.58 standard deviation and satisfaction with 4.63 
mean and 0.53 standard deviation got also a positive response from the participants. These indicate the success of the web portal and that it met user requirements. The web portal passed all tests done while running on a remote server based on user requirements as shown in Table IV. System testing was done to verify if the developed system met the business requirements of the end users. It is the outcome of many integrated and tested functional units that have successfully passed through the integration process. It does not deal with structural features of source codes but the functional features which are visible to the end user [17]. The system passed all the integration tests done while running on a remote server. The information submitted into the database from the web-based system could be successful retrieved as seen in Table IV.

\section{CONCLUSION}

The study shows that the developed web portal for ornamental plants and flowers is a good alternative according to the results obtained from the first and final phase tests of user acceptance. The adoption of the web portal will pave the way for biodiversity institutions to digitize their collection of species of ornamental plants and flowers and will also connect small scale farmers to the regional and international market. The user acceptance indicates that stakeholders face several challenges in the horticulture sector that need to be addressed by solutions as this web portal. The developed web portal has facilitated the inventory, mapping and digitization of the variety of species of ornamental plants and flowers in Arusha. It is accessible online by all stakeholders, it will help vendors conduct their businesses online, and will also provide the Arusha City Council representatives with baseline information from which informed plans and decisions can be made. In future work, other stakeholder groups could be added, such as representatives from the tourism industry that require other services in the horticulture sector such as using computer vision to identify the various species of ornamental plants and flowers automatically.

\section{REFERENCES}

[1] A. Tatnall, Web Portals: The new gateways to internet information and services, Idea Group Inc., 2005

[2] M. Hemmati, H. Hosseini, "Effect of IT application on project performance focusing on the mediating role of organizational innovation, knowledge management and organizational capabilities", Engineering, Technology \& Applied Science Research, Vol. 6, No. 6, pp. 1221-1226, 2016

[3] V. Kelly, C. Donovan, Agricultural statistics in sub-Saharan Africa: Differences in institutional arrangements and their impacts on agricultural statistics systems. A synthesis of four country case studies, Michigan State University, 2008

[4] OECD, "Agriculture in sub-Saharan Africa: Prospects and challenges for the next decade", in: OECD-FAO Argicultural Outlook 2016-2025, OECD-FAO, 2016

[5] Match Maker Associates, Horticulture study: Phase1: Mapping of production of fruits and vegetables in Tanzania, Embassy of the Kingdom of Netherlands, 2017

[6] HODECT, Tanzania horticultural development strategy 2012-2021, HODECT, 2012

[7] C. Ardito, M. F. Costabile, M. De Marsico, R. Lanzilotti, S. Levialdi, T. Roselli, V. Rossano, "An approach to usability evaluation of e-learning applications", Universal Access in the Information Society, Vol. 4, No. 3 , pp. $270-283,2006$
[8] S. Vairamuthu, S. Margret Anouncia, "Reconnoitering students' satisfaction of an online based assessment system to improve usability using PSO: An examination into a problem solving and programming course", Engineering, Technology \& Applied Science Research, Vol. 6, No. 5, pp. 1207-1211, 2016

[9] J. B. Sugau, A. M. A. Mustapeng, N. A. M. Yusof, "Application of the Brahms software as a botanical database management system in Sandakan Herbarium", International Borneo Research Council Conference, Kalimantan Timur, Indonesia, August 20-21, 2016

[10] R. Muhtaseb, K. Lakiotaki, N. Matsatsinis, “Applying a multicriteria satisfaction analysis approach based on user preferences to rank usability attributes in e-tourism websites", Journal of Theoretical and Applied Electronic Commerce Research, Vol. 7, No. 3, pp. 28-48, 2012

[11] A. Hussain, S. Aliyu, M. M. Barakat, F. Maki, "Assessing and testing the usability of student portal", 3rd International Conference on Applied Science and Technology, Georgetown, Malaysia, April 10-12, 2018

[12] S. Bryson, D. Bulterman, T. Catarci, W. Citrin, I. Cruz, E. Glinert, J. Grudin, J. Hollan, Y. Ioannidis, R. Jacob, B. John, D. Kurlander, B. Myers, D. O. Randy, S. Shieber, B. Shneiderman, J. Stasko, G. Strong, K. Wittenburg, "Strategic directions in human-computer interaction", ACM Computing Surveys, Vol. 28, No. 4, pp. 794-809, 1996

[13] B. A. Myers, B. Rosson, "Survey on user interface programming", Conference on Human Factors in Computing Systems, Monterey, USA, May 3-7, 1992

[14] J. Nielsen, Usability 101: Introduction to Usability, available at: https://www.nngroup.com/articles/usability-101-introduction-tousability, 2012

[15] S. Angilella, S. Corrente, S. Greco, R. Slowinski, "MUSA-INT: Multicriteria customer satisfaction analysis with interacting criteria", Omega (United Kingdom), Vol. 42, No. 1, pp. 189-200, 2014

[16] M. Hub, M. Zatloukal, "Model of usability evaluation of web portals based on the fuzzy logic", WSEAS Transactions on Information Science and Applications, Vol. 7, No. 4, pp. 522-531, 2010

[17] S. Nidhra, J. Dondeti, "Black box and white box testing techniques: A literature review", International Journal of Embedded Systems and Applications, Vol. 2, No. 2, pp. 29-50, 2012 